\title{
The genesis of Collegiate Membership: a personal account by the first Chair of the Collegiate Members' Committee
}

\author{
MA Eastwood \\ Retired Gastroenterology Consultant and Reader in Medicine, University of Edinburgh, Edinburgh UK
}

ABSTRACT Just over 40 years ago, the then President of the Royal College of Physicians of Edinburgh, Christopher Clayson, responded to the publication of a Royal Commission on Medical Education by setting up a College Committee under the chairmanship of John Halliday Croom. This is a personal account of, and reflections on, the workings of that important committee, the College Council whose work led to the introduction of Collegiate Membership and the Collegiate Members' Committee of which I was the first Chair. This development led to the RCPE becoming much more concerned with, and responsive to, the needs of doctors in training and had a wider, positive impact upon medical training and education in the UK.

KEYWORDS Collegiate membership, John Halliday Croom, Todd commission

\author{
Correspondence to MA Eastwood \\ 10 Cross Street \\ Beverley \\ East Riding \\ Yorkshire HUI 9AX \\ UK
}

e-mail majeastwood@btinternet. com

DECLARATION OF INTERESTS No conflict of interests declared.

\section{BACKGROUND AND HISTORICAL CONTEXT}

The Royal College of Physicians of Edinburgh (RCPE) was granted its Royal Charter by Charles II in I68I.The Charter stated that in order to practise, an approved physician had to demonstrate ability and fitness by a recognised examination, conducted by examiners with the requisite power and authority for this purpose. The influence of the College was originally defined within a five mile radius of the centre of Edinburgh. ${ }^{1,2}$

In Edinburgh, clinical care was also provided by surgeons, barbers and apothecaries who prescribed and dispensed medicines. From the early 16th century, surgeons, apothecaries and others were required to be examined in order to become freemen or members of the Incorporation of Surgeons and Barbers, which had been founded in 1505. Licentiateship of the Royal College of Physicians, introduced in 1682, was intended to raise the standards of medical care, by making all candidates (except Scottish graduates) pass an examination.

Originally the practice was to give a licence and raise an individual to Fellowship in one session but in 17/4 this waiting period was extended to one year. For the first 200 years of the College's existence the terms Fellowship and membership were used interchangeably in College papers. In 1822 the term 'member' was forbidden for Licentiates.

In the early nineteenth century, physicians were tending not only the more economically fortunate in the community but were also engaged in philanthropic activities. Surgeons and apothecaries dealt with the bulk of what might be called general practice; there were still a large number of 'quacks', some without qualification but claiming to have been apprentices.

The Medical Act (I858) and its effect on the College

The Medical Act ( 1858 ) brought about the establishment of the General Council of Medical Education and the legal Registration of qualified Medical Practitioners. With the passing of the Medical Act, the College was faced with problems and adjustments which were as fundamental as they were far reaching. Central to this was a wish to establish and maintain the pre-eminence of the physician.

The 1858 Act put at risk many who had trained as surgeons and apothecaries and were members of an Apothecaries' Society, so the College admitted them as Licentiates. Thereafter candidates for Licentiateship had to give evidence of having attended approved classes for four years and had practiced medicine in a hospital with more than 80 beds for more than two years. Licentiates could then be included in the Medical Register and practise anywhere in the British Empire. In 1859, the Colleges of Surgeons and Physicians in Edinburgh combined to award a double qualification in medicine and surgery; in 1884 this was extended to a triple qualification in partnership with the Faculty of Physicians and Surgeons of Glasgow. Two years later progress continued when women were allowed to sit the 
conjoint qualification examination. Famous doctors who qualified included Elsie Inglis and the cricketer W.G. Grace. $^{3}$

In I86I a new Charter was drafted before the College. Prior to being nominated for Fellowship, candidates had to have been a Licentiate for at least one year. Between 1829 and 1857 there were 70 Licentiates within Edinburgh and 82 outside Edinburgh admitted to Fellowship. The reasons for Edinburgh practitioners wishing to become Fellows were the higher status, the social benefits, and access to the excellent library and reading rooms which Fellowship conferred. Because, from 1858, a university medical degree was sufficient licence to practise medicine, the College had a problem in recruiting Fellows. The 186I Charter allowed for a new group within the College - Members - a position that lay between Licentiates and Fellows.

The College then agreed to abolish the label of Licentiate and to substitute Member status, thereafter examining applicants for the Membership or Fellowship. To qualify for Membership the candidate had to provide evidence of approved medical training and qualification and satisfy the College with his/her knowledge of medicine and general science. A motion for election was then made and seconded at a quarterly meeting of the College.

\section{Candidates for Membership}

The number of candidates for the membership examination increased considerably after World War II; from 37 in 1925, to 349 in 1948, then 1031 in 1959 and 1418 in 1965. The increase was due in part to the backlog created by the War as well as a response to the establishment of the National Health Service in 1948 and the assured place it gave to consultants and specialists. A requirement of the new NHS was that candidates for hospital consultant posts should have higher qualifications. In addition, almost two thirds of the candidates came from outside the UK. In 1962 there were 825 foreign candidates and the examination pass rate was between 19 and $29 \%$. The increased numbers placed a great strain on the College's facilities, so much so that written examinations had to take place in University accommodation.

Inevitably, the provision of clinical cases for so many candidates, and the maintenance of examination standards, was a real problem. More than 13 hospitals across Scotland were used for clinical examination.' Patients with interesting histories and physical signs effectively became a bank of examination patients, willing to come in for the period of the examinations. These patients often became practised in the art and would give the candidates a full history when given the chance. With courtesy and care by the candidate, such 'cases' could be very helpful and supportive; in a way, this subtly differentiated those candidates who were good at communicating with patients from those who were not.

Another problem was the phenomenon of 'multiple diplomatosis', wherein junior doctors, wishing to maximise their career possibilities throughout the United Kingdom were encouraged to sit membership examinations in two or even three of the Medical Royal Colleges.

\section{CHANGES IN MEDICAL EDUCATION}

\section{The Todd Royal Commission of 1968}

The Royal Commission on Medical Education of 1968, under the chairmanship of LordTodd, was set up to address concerns about insufficient numbers of UK trained doctors, and an increasing reliance on overseas graduates. ${ }^{4}$

Some comments in the Todd Report were critical of the Royal Colleges and the low pass rate in their higher professional examinations. The pass rate for the FRCSEd and the MRCP Edin at each examination was then about $25 \%$. This was regarded as unacceptably low and an unfair barrier to specialisation. The Todd Commission suggested that the pass rate should be much higher and indeed almost automatic, being based essentially on reports of satisfactory progress from a postgraduate's teachers. Todd assumed that such teachers existed and that they were in a position to make such judgements.

\section{Consequences of the Todd Commission Report}

In 1968, the RCPE had 938 Fellows and 3,358 Members. Members were not involved or represented in the workings of the College. The examination to become a Member of the College was different from other colleges in requiring a demonstration of competence not only in general medicine but also in a speciality. Preparation for the exam placed a great burden on the candidates. Often those working in Edinburgh Medical Units formed small groups for mutual support and education.

Maurice Henry Pappworth (1910-1994) developed a systematic approach to the membership examination. He was shocked by the low pass rate and said this reflected poor teaching in British medical schools. He set out to teach clinical medicine to postgraduates and focused on the art of examining patients and impressing examiners. He charged $f \mid$ for a two hour session and his methods soon had impressive results (the pass rate for the doctors he tutored was said to be over $50 \%$ ). Part of Pappworth's technique was to ask candidates coming out of the College examinations what cases they had seen and what questions they had been asked. He then forewarned succeeding candidates. This caused anxious 
examiners to move patients and beds around the ward to try to maintain the diagnostic challenge of the examination. Pappworth also wrote a popular textbook on the art of clinical examination. ${ }^{5}$

\section{MRCP(UK) and Collegiate Membership}

The Common Part I Membership examination of the three United Kingdom Royal Colleges of Physicians began in 1968, following which the designation of MRCP(UK) was introduced.The President of the London College proposed the introduction of collegiate membership whereby, for a small fee, Members could become more involved in the activities of the London College. They would receive notices of activities and attend functions at a reduced cost. The response of the Glasgow College was similar.

The reaction of the Council of the RCPE, under the Presidency of Dr Christopher Clayson, was to form a committee, chaired by Dr John Halliday Croom, to propose a response. It is just over 40 years since the Croom Committee made its recommendations which transformed the College. ${ }^{6}$ Prior to this the College had been a staid institution, inaccessible to non-Fellows. Being awarded the Fellowship was an honour, giving entrance to an elite club, access to an excellent library and Fellows' dinners. The Croom Committee report was to change that considerably for the better.

\section{REFLECTIONS ON EARLY COLLEGIATE MEMBERSHIP}

While I was working as a lecturer in the Department of Therapeutics in Edinburgh, I was surprised to be asked by my chief, Professor Girdwood, what I thought of the RCPE; a topic to which I had not given much thought since gaining my MRCP in 1966. My tentative, unenthusiastic reply resulted in an invitation for my thoughts to be presented for publication in the College Chronicle. This journal had a forbidding warning on the contents page, 'that the information contained in the Chronicle was restricted to Fellows and Members and was not to be conveyed to the general public or to other journals'. I wrote of the remoteness of the College - 'an empty mausoleum with large green doors always closed'.

\section{The Croom Committee}

The Croom Committee comprised twelve Fellows and four Members. It consisted entirely of male physicians a sign of the times and hard to imagine today. Character sketches of the key participants are included in Appendix I (available online). I was asked to be one of the four Members on the committee, which had four subgroups (each consisting of one Member and three Fellows).

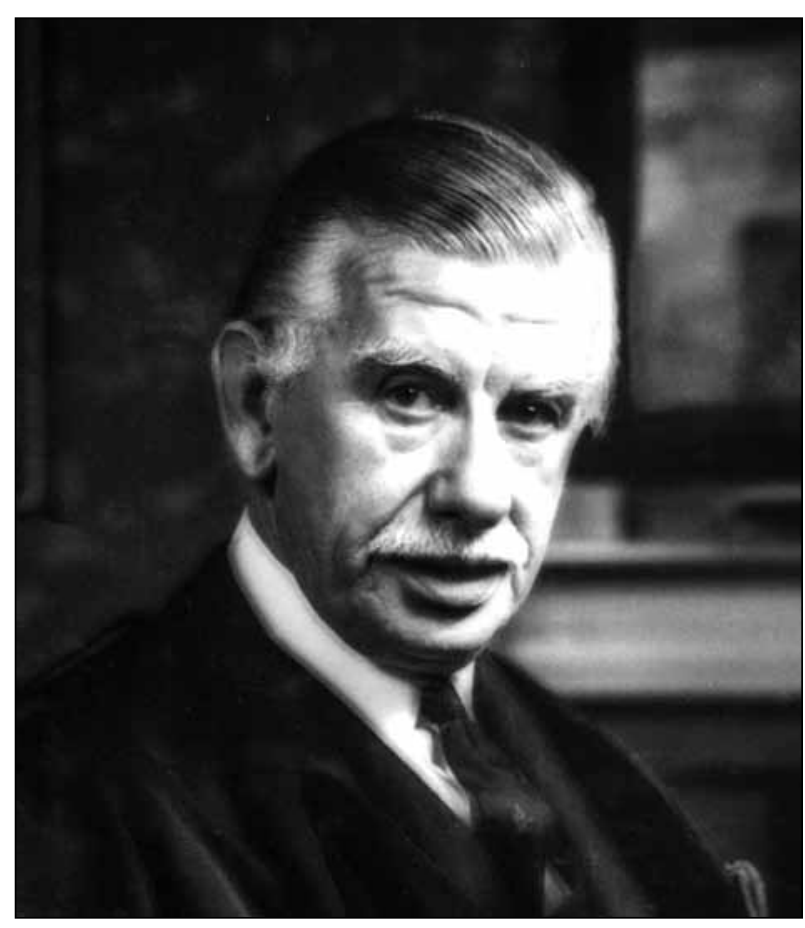

FIGURE I John Halliday Croom

These subgroups dealt with:

I. Postgraduate medical education and the assessment of progress in postgraduate training.

2. The relationship of the College to other bodies; the role of the College in medical research; the College library and the College building.

3. The Membership and Fellowship of the College; College Meetings.

4. Hospital staffing structure; the recognition of posts for postgraduate training; vocational registration.

Being a member of the Croom Committee was an eye opener. My first important discovery was the deep affection in which the Fellows held the College. This Committee had to succeed. The subgroups worked in a purposeful manner and the meetings were amiable and produced sensible ideas. Even now the report reads in a thoroughly contemporary way.

The Croom Committee report came out in October 1969, ${ }^{6}$ and its recommendations profoundly changed the College and its activities. The main proposals were:

- Agreement with the Todd report on professional standards and with proposals for a 3-year period of general professional training (not assessed) followed by specialty training for a further 4 years.

- Endorsement of independent inspection of training centres and for continuing medical education throughout a doctor's career (whilst noting the likely difficulties in practice).

- Proposal that there be a national authority for specialty training but with much local autonomy. 
- Recommendation for more scientific meetings in partnership with other Colleges, NHS departments and the universities. The Committee pointed out that this inevitably required expansion of the space for large and small meetings within the College in Queen Street.

- $\quad$ Strong advice to support reciprocity of membership with other Colleges and eventually a common part II examination

- Above all, the Committee recommended the formation of the category of 'Collegiate Membership', with additional benefits for those who became Collegiate Members, plus involvement in the College committees.

These proposals required development of the existing College building, which in time was to be brilliantly achieved. There were to be changes in the Membership examination and more importantly Members' activities. Collegiate Membership was to be created to allow Members to engage in the activities and affairs of the College; in particular two Members were to be elected to the College Council.

\section{The Collegiate Members Committee (CMC) and its first proposals}

The first Collegiate Members' Committee proved to be a stimulating group of individuals. There were nine members drawn from all over Scotland: I was the first Chairman, with Cyril Cohen as Vice Chairman and John Davidson as secretary. The other members were James Gray, Alexander Macqueen, John Nimmo, Bryan Stack, Robert Walker and Robert (Bertie) Wood. We were all determined to make this new institution work. John Nimmo and Robert Wood were later conspicuous in their services to the College as Registrar and Treasurer, respectively.

Our first task was to draw up a constitution and present our proposals to Council.? By this time John Halliday Croom was President so it was a straightforward task to present our list and have it rubber stamped. It also raised the possibility of a shift in ownership of the College. Would it be Council and Fellows, or Council, Fellows and Collegiate Members?

The CMC had agreed we would recommend that there would be a Collegiate Member on each College Committee, with the exception of the Fellowship Committee, which elected Members to Fellowship. This was to be discussed at a Council Meeting. I was amazed to read in our submission that somehow the recommendation concerning the Fellowship Committee had been changed; the relevant part now read 'to include membership of the Fellowship Committee'. How this had happened, I had no idea. I, barely recovered from a very recent laparotomy, came to my first Council

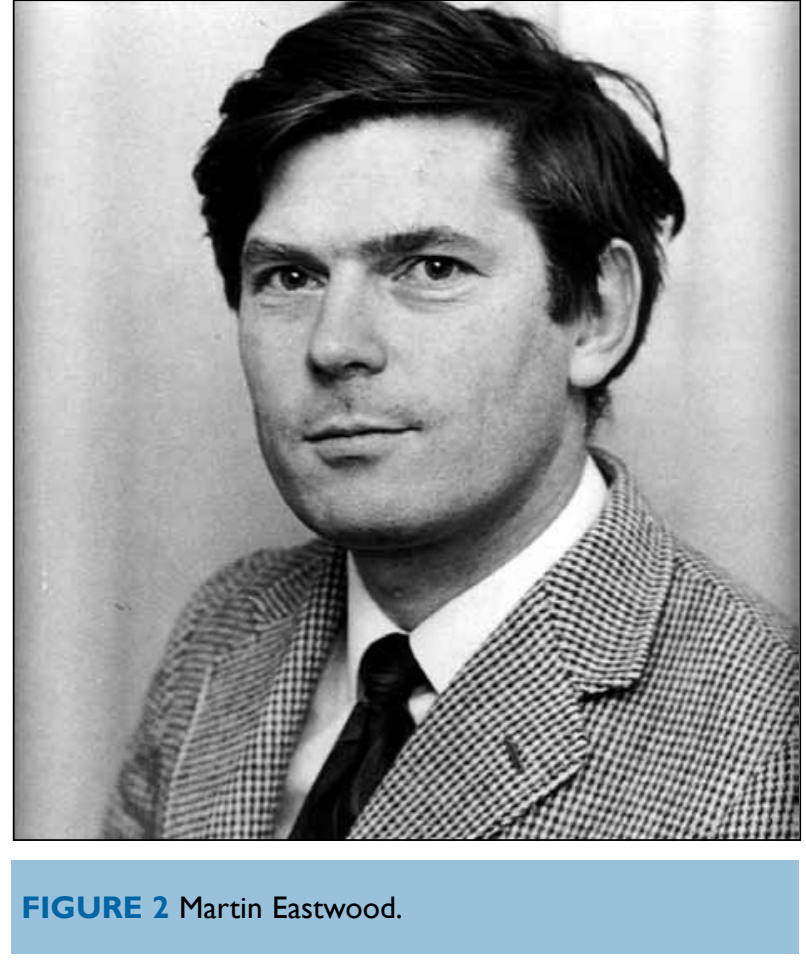

meeting poorly prepared and fragile. I had to make up my mind quickly. Ought I remain loyal to the misprint and to the author of the mistake, or be sensible and retract? I made the wrong decision and supported the submitted document.

The suppressed anger of some of the members of Council at the intrusion of Collegiate Members was then unleashed. A heated discussion ensued. At one point it looked as though Members would be barred from the College! The meeting was saved by the urbane Bobby Marquis gently talking until the anger had settled. After this, the Council accepted most of the CMC's proposals, although Collegiate Members were not included on the Fellowship Committee.. Subsequently, I regularly met John Halliday Croom in extremely productive meetings and the concept of Collegiate Membership became accepted by the College.

The outcome: development of Collegiate Membership.

The College was transformed by the vision of Christopher Clayson and John Halliday Croom and his Committee. Collegiate Membership has become a precursor to Fellowship and, at the end of 2013, the College had 848I Fellows and 2791 Collegiate Members. In recent years, the Trainees \& Members' Committee (T\&MC), the successor to the original Collegiate Members' Committee, has become one of the most active and influential trainee groups in the UK. The T\&MC was responsible for developing the widely regarded Charter for Medical Training in $201 \mathrm{I}$ and its views are increasingly sought by those involved in 
delivering medical training, education and examinations in the UK to ensure that the views and needs of medical trainees are considered at the highest level. In parallel, it runs a programme of educational events for doctors in training including the increasingly popular series of Evening Medical Update presentations which are routinely videolinked to more than 40 sites in the UK and attract audiences in excess of 500 delegates per event. None of this would have been possible without the Croom Committee.
And myself? I treasure my contact with truly great men, especially John Halliday Croom. I have a cherished memento of these times, a pewter mug given to me by the Collegiate Members Committee on my retirement from Chairmanship of their Committee.

\section{Acknowledgements}

I am grateful to lain Milne and Estela Dukan of the College Library for their generous help in retrieving documents and to the Editorial Board of the Journal for helpful comments.

\section{REFERENCES}

I Craig WS. History of the Royal College of Physicians of Edinburgh. Oxford: Blackwell; 1976

2 McCrae M. Physicians and Society. Edinburgh: John Donald; 2007.

3 Dingwall HM. The Triple Qualification examination of the Scottish medical and surgical colleges, 1884-1993. J R Coll Physicians Edinb 2010; 40: 269-76. http://dx.doi.org/I0.4997/JRCPE.2010.317

4 Royal Commission on Medical Education. London: Her Majesty's Stationery Office; 1965-68.
5 Pappworth MH. A Primer of Medicine. Oxford: Butterworth; 1960.

6 Report of College Committee to consider the future of the College. Edinburgh: Royal College of Physicians of Edinburgh; 1969.

7 Eastwood MA. Collegiate Membership. The first year. The Royal College of Physician's Chronicle 1972: 6-8. 